\title{
MODELING OF THE SURFACE STATIC DISPLACEMENTS AND FAULT PLANE SLIP FOR THE 1979 IMPERIAL VALLEY EARTHQUAKE
}

\author{
By Martin A. Slade, Gregory A. Lyzenga, and Arthur Raefsky
}

\begin{abstract}
Synthesis of geodetic and seismological results for the 1979 Imperial Valley earthquake is approached using three-dimensional finite element modeling techniques. The displacements and stresses are calculated elastically throughout the modeled region. The vertical elastic structure in the model is derived from compressional and shear wave velocities as used in the seismic data analysis (Fuis et al., 1981) combined with a sediment density profile. Two strategies for applying initial conditions are followed in this modeling. In the first strategy, a sample seismological estimate for fault plane slip is used to predict the resultant surface motions. We show that the geodetic strain results over distances of tens of kilometer from the fault (Snay et al., 1982) are basically consistent with the model seismic fault displacements. Geodetic results from within a few kilometers of the fault trace (Mason et al., 1981) seem to require more slip at shallow depths than appears at seismic time scales. This is consistent with the occurrence of aftercreep at shallow depths in less well-consolidated material, which would bring surface displacements into line with maximum slip at depth, but not greatly affect the net moment.

In the second strategy, we consider stresses on the fault plane, rather than displacements, as model variables. To constrain this part of our numerical modeling, we assume that the fault driving stress is governed by ambient tectonic stress and an opposing Coulomb friction derived from experiment. The coseismic stress drop from point to point on the failed fault is given by the difference between the tectonic shear stress and the frictional stress. After arriving at such a uniform model which adequately represents the Snay et al. results, we further modify a small region near the seismic "asperity" to make the fault plane motions qualitatively and quantitatively resemble the model of coseismic motions used in the first strategy. The observed offset on the fault trace (Sharp et al., 1982) is approximated in this final stress-driven model by removing the driving stress on the southern third of the fault.

Thus, the principal features of the coseismic slip pattern are explained by a stress-driven fault model in which: (a) a spatially unresolved asperity is found equivalent to a stress drop of $18 \mathrm{MPa}$ averaged over an area of $15 \mathrm{~km}^{2}$, and (b) driving stress is essentially absent on the fault segment overlapping the $\mathbf{1 9 4 0}$ earthquake rupture zone.
\end{abstract}

\section{INTRODUCTION}

The Imperial Valley is one of the most seismically active regions in California and represents an important transition zone as follows. The character of the plate boundary in the Imperial Valley is predominantly strike-slip, with east-west extensional tectonics superposed. To the south in the Gulf of California, the plate boundary is a spreading ridge-transform fault system (Lomnitz et al., 1970; Elders et al., 1972). Northward from the Imperial Valley, the Transverse Ranges are characterized by north-south compression of $\sim 0.17 \mu$ strain/yr (Savage et al., 1981). The Salton trough in general appeared to be in uniaxial north-south contraction at the rate of 0.3 strain/yr, with no rift-opening strain perpendicular to the axis of the 
trough (Savage et al., 1979). However, the directions and rates of strain in Southern California may be time variable, since the more recent observations (Savage et al., 1981) find these strains are now comparable. In order to study the regional tectonics of this important area, we have performed numerical modeling, using the finite element technique, of the most recent significant earthquake there.

The 15 October 1979 , Imperial Valley earthquake was a large event $\left[M_{L} 6.6\right.$ (Chavez, 1982)] in a well-instrumented area with a fairly well-characterized vertical seismic velocity structure (Fuis et al., 1981). The data from this event and its aftershocks have been the subject of a large number of investigations (see, e.g., U.S. Geological Survey Professional Paper 1254, 1982). Our finite element studies attempt to synthesize the results of several specific analyses of the Imperial Valley main event into a self-consistent static description of the coseismic displacements and stresses.

The strategy pursued in this work consists of two principal steps (Figure 1). In the first step, we take the seismologically derived (Hartzell and Heaton, 1983) coseismic fault slip as a function of position in the fault plane and apply this directly to a three-dimensional dislocation model. Since this approach entails considerable inhomogeneity, both in the distribution of slip and in constitutive parameters, we have chosen to employ the finite element method for these calculations. The surface displacements and strains obtained from this step of the modeling is then compared with available geodetic data, with the purpose of identifying components (if any) of the observed geodetic changes which are not explained by the seismic slip. This step of the modeling, therefore seeks to work from the seismic slip observation toward an insight into any unmodeled processes occurring in the fault zone.

In the second step of the modeling presented here, we invert this strategy by beginning with a physical model of stresses and constitutive parameters, and subsequently perturb it in order to reproduce the observed fault slip (and by assumption, geodetic displacements). These two approaches are complementary, but not redundant or trivially equivalent. This is apparent because for any given set of seismological and/or geodetic data, there exists a broad set of nonunique physical models to explain these.

The purpose of the first step then, is to provide an adequate empirical description of the event under consideration, while the second seeks to select a physically plausible scenario to reproduce this description. This finite element modeling procedure does not, therefore represent a formal inversion for very specific details in the local stress field, but rather is an attempt to reconcile a range of observational data within a basic physical framework.

\section{BACKGROUND MODEL INFORMATION}

Our analysis of the 1979 coseismic motions utilizes as input the results from seismological studies. A brief description of these is given below.

All of the models have in common a vertical elastic profile derived from the vertical velocity structure of Fuis et al. (1981), as used in the seismic data analysis (Figure 2). The density profile given in Table 1 as a function of depth (Hartzell, personal communication, 1982), was used. The model values used here for Lamé's modulus $\lambda$ and shear modulus $\mu$ are also given in Table 1 . The depths in Table 1 are also the vertical divisions of our finite element grid.

The finite element models constructed are compared with various results, as explained below, in order to judge their success. The coseismic displacements on the Imperial fault obtained from analysis of a combination of strong-motion and 
teleseismic data by Hartzell and Heaton (1983) are used as input to the dislocation model. Figure 3 (top) shows the seismically determined strike-slip displacements interpolated onto the nodal points of our finite element grid (discussed below), where the contour levels are in centimeters. The values shown are half the dislocation; these values are imposed in opposite senses (for right-lateral motion) on the opposing fault walls, by employing the "split node" finite element procedure de-
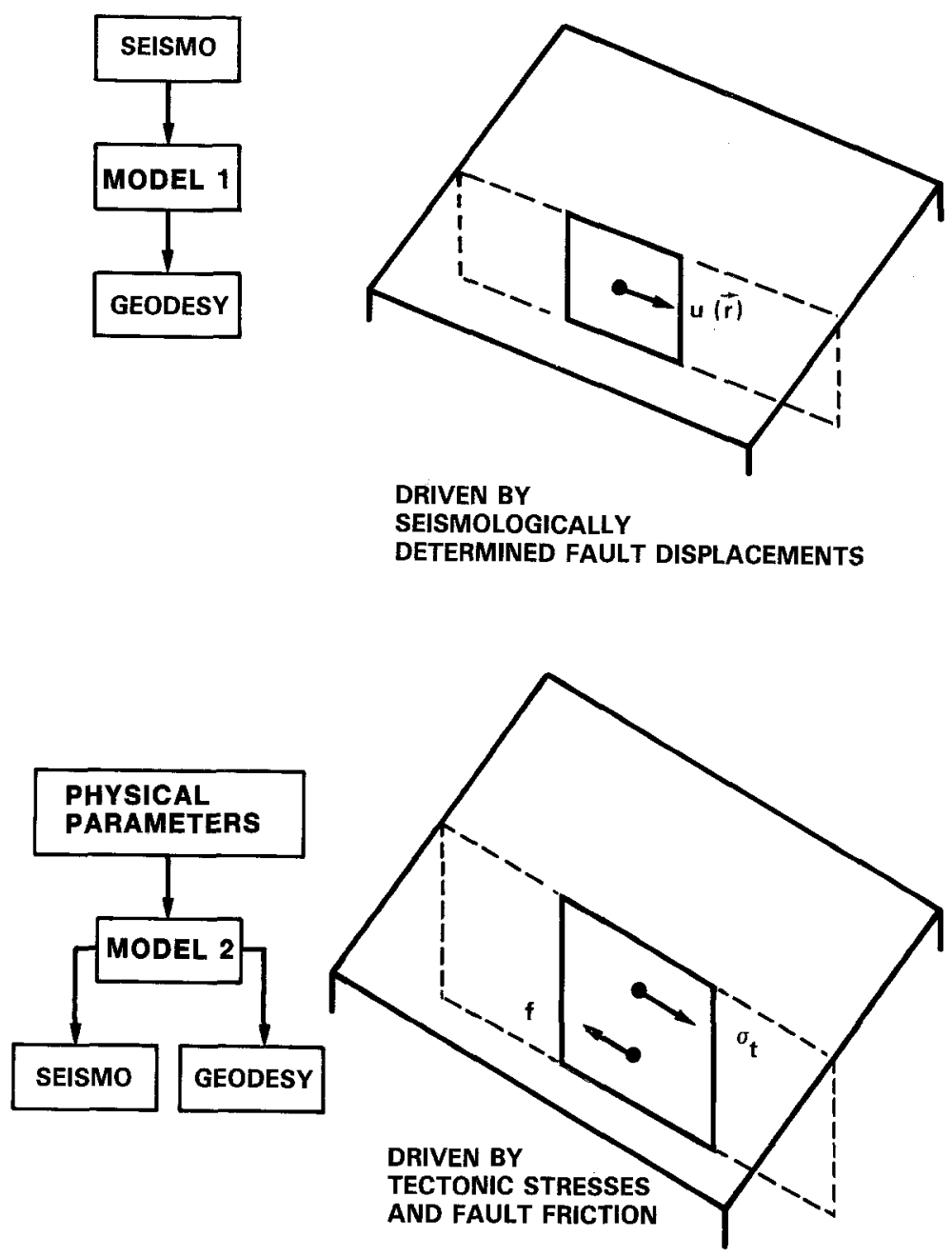

FIG. 1. Schematic diagram outlining the two types of finite element modeling considered in this paper.

scribed by Melosh and Raefsky (1981). The dip-slip components (Figure 3, bottom) are also used in the dislocation modeling, but they are much smaller than the strikeslip values.

Examination of the strike-slip displacements shows a region of largest displacement, at a depth of 5 to $7 \mathrm{~km}$ and $2.5 \mathrm{~km}$ north of our arbitrary origin (which is on the Imperial fault at latitude $32^{\circ} 46^{\prime} 50.8^{\prime \prime} \mathrm{N}$, longitude $115^{\circ} 26^{\prime} 40^{\prime \prime} \mathrm{W}$ ). This region is characterized below as the asperity. The asperity is the fault region which because 


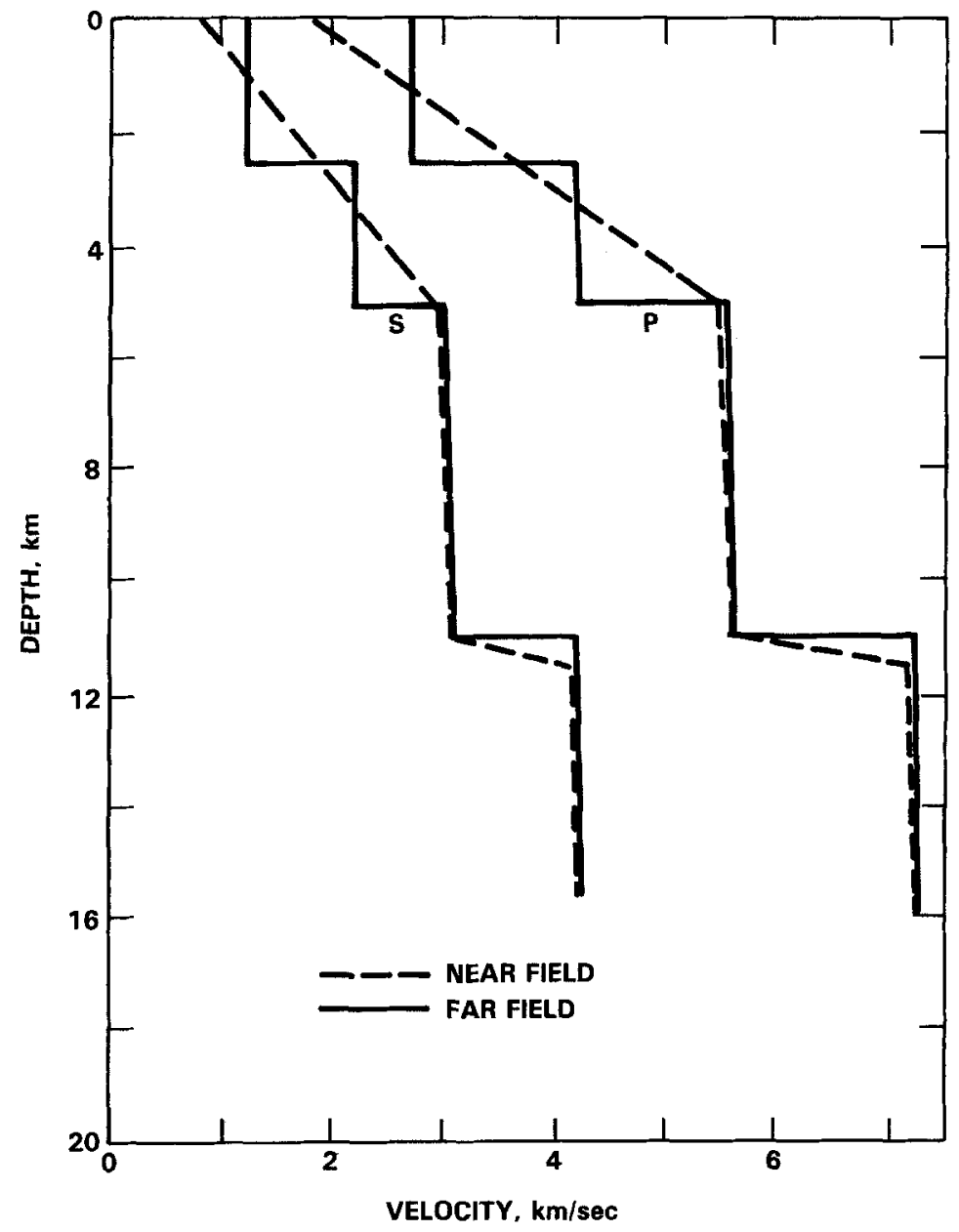

FIG. 2. The variation with depth for compressional velocity $V_{P}$ and shear velocity $V_{s}$ in the Imperial Valley as used in the seismic data analysis.

TABLE 1

DENSITY Profile

\begin{tabular}{cccc}
\multicolumn{4}{c}{ DENSITY PROFILE } \\
\hline $\begin{array}{c}\text { Depth } \\
(\mathrm{km})\end{array}$ & $\begin{array}{c}\rho \\
\mathrm{Kg} / \mathrm{m}^{3} \\
\times 10^{-3}\end{array}$ & $\begin{array}{c}\mu \\
(\mathrm{Pa})\end{array}$ & $\begin{array}{c}\lambda \\
(\mathrm{Pa})\end{array}$ \\
\hline $0-2.5$ & 1.90 & $2.9688 \times 10^{9}$ & $6.9065 \times 10^{9}$ \\
$2.5-5.0$ & 2.20 & $1.2672 \times 10^{10}$ & $1.7248 \times 10^{10}$ \\
$5.0-7.5$ & 2.55 & $2.2950 \times 10^{10}$ & $3.1238 \times 10^{10}$ \\
$7.5-10.5$ & 2.55 & $2.2950 \times 10^{10}$ & $3.1238 \times 10^{10}$ \\
$10.5-30.0$ & 2.80 & $4.8348 \times 10^{10}$ & $4.8348 \times 10^{10}$ \\
\hline
\end{tabular}

of either constitutive properties or loading history or both, suffered the maximum stress drop during seismic failure.

The use of the seismological inversion results of Hartzell and Heaton is not to be construed that we have shown that these are necessarily superior in any way to other results, e.g., Archuleta (1982a) or Olson and Apsel (1982). We have not 

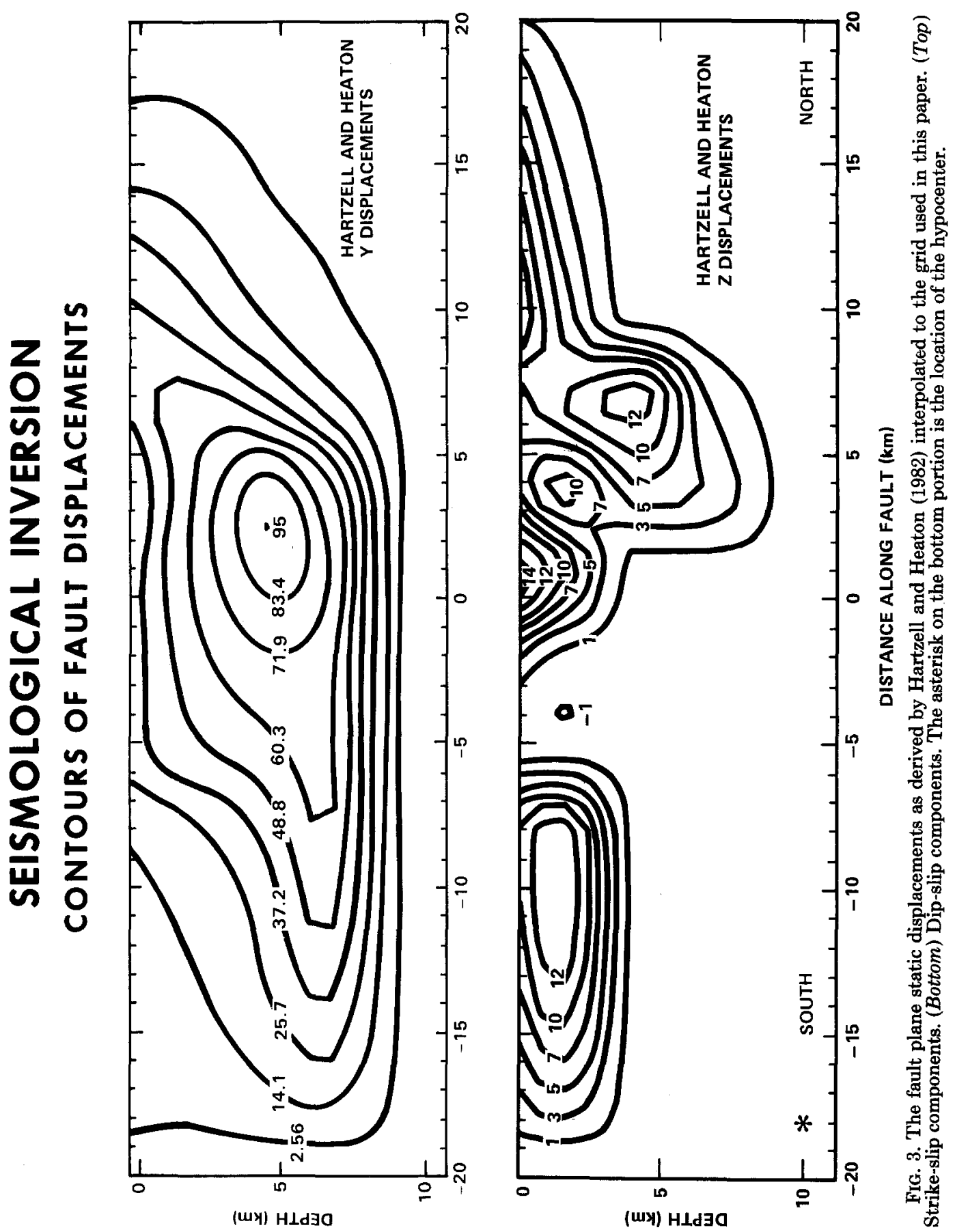
attempted to do a definitive study on this question. Indeed, the accuracy and coverage of the currently available geodetic data do not permit such an evaluation at this time. The results of Hartzell and Heaton merely provide a detailed and convenient input source to test. Examination of other such solutions would be redundant and add confusion to the central questions.

After presentation of the dislocation model results, we compare these with selected geodetic observations and then discuss efforts to construct stress-driven physical models consistent with the above. In the section which follows, we provide a brief description of the finite element procedures employed in this work.

\section{Finite Element Modeling}

The finite element programs used for this study were derived from the basic three-dimensional elasticity formulation using linear "brick" elements (Zienkiewicz, 1977), and an external storage solution scheme (Wilson and Dovey, 1978) in order to handle the very large equation systems of the three-dimensional problems. From this fundamental elastic formulation, a general code for treating linear and nonlinear viscoelasticity has been developed, as described by Melosh and Raefsky (1980) (MR80) for the two-dimensional quasi-plane strain case. The modifications necessary to generalize to fully three-dimensional calculations are described below. The matrix of elastic properties $\underline{D}$, as used in MR80 equation (10), is now given by

$$
\underline{D}=\frac{E}{(1+\nu)(1-2 \nu)}\left[\begin{array}{cccccc}
(1-\nu) & \nu & \nu & 0 & 0 & 0 \\
\nu & (1-\nu) & \nu & 0 & 0 & 0 \\
\nu & \nu & (1-\nu) & 0 & 0 & 0 \\
0 & 0 & 0 & \frac{1-2 \nu}{2} & 0 & 0 \\
0 & 0 & 0 & 0 & \frac{1-2 \nu}{2} & 0 \\
0 & 0 & 0 & 0 & 0 & \frac{1-2 \nu}{2}
\end{array}\right]
$$

where $\nu=$ Poisson's ratio and $E=$ Young's modulus.

The grid used for this finite element work is shown in map view in Figure 4. The plot is scaled in units of hundreds of kilometers. The heavy bar between $\pm 20 \mathrm{~km}$ on the ordinate is the trace of the modeled fault. The full grid is composed of six such planes stacked normal to the view shown, to produce five complete layers of parallelepiped "elements". The layer thicknesses are given by Table 1.

The class of models in which specified dislocations were imposed was calculated using the "split node method" of Melosh and Raefsky (1981) in order to introduce an arbitrary spatially variable slip on the fault surface. Such a modeling procedure allows direct calculation of the static surface displacements for any given hypothetical distribution of slip on the fault. This may in turn be compared with available geodetic data in a heuristic "fitting" procedure.

The stress-driven finite element models are distinct from the specified dislocation models in implementation as well as purpose. In this class of models, we consider the fault plane to be a surface upon which nodal displacements are either unconstrained or inhibited, depending on whether such nodes lie within or outside the zone of seismic rupture. The assumed symmetry of the model allows calculations to be carried out for the region on one side of the fault, with complementary motions occuring on the opposite side. 
The principal input variables to this class of models are the tractions applied to the fault surface. Interpreted within the context of a particular model of crustal stress and constitutive makeup, this driving traction is intended to represent the net effect of tectonic stresses, frictional forces, and any other stresses bearing on the amount and variation of seismic slip.

\section{FINITE ELEMENT GRID}

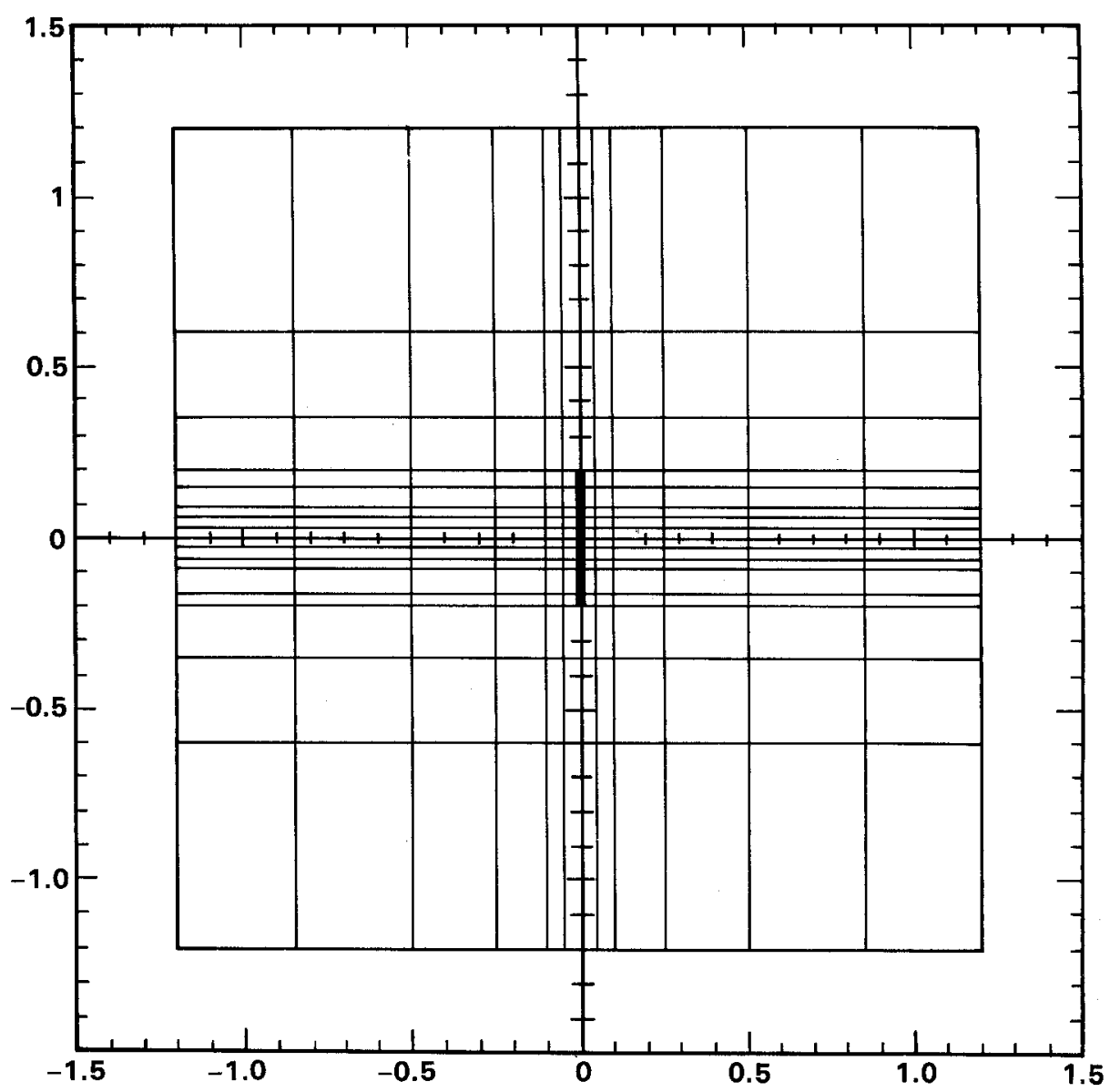

Fig. 4. Top view of the $x-y$ plane of the finite element grid. The full grid consists of six such planes stacked normal to this plane in the $z$ direction. The planes are located at the boundaries given in Table 1. The origin is at latitude $32^{\circ} 46^{\prime} 50.8^{\prime \prime} \mathrm{N}$, longitude $115^{\circ} 26^{\prime} 40^{\prime \prime} \mathrm{W}$. The fault trace (heavy bar) strikes north $38^{\circ} \mathrm{W}$.

\section{Model Results and Comparison with ObServation}

Figure 5 shows the surface motions predicted from the fault plane displacement of Hartzell and Heaton. The familiar pattern of a strike-slip fault can be clearly seen. These same displacements are presented in another form in Figure 6. Here, the finite element results are directly compared with the geodetic observations of Snay et al. (1982), in the format of the latter, for ease of comparison. This geodetic 
data set comes from the NGS triangulation and trilateration network data, which contain more regional (but sparser) samples of the surface strains, as shown in Figure 6. The orientation of the line segments is the computed direction of maximum right-lateral shear strain, or more precisely, the direction of the initial side of the right angle which experiences maximum change. The length of the line segment is proportional to the amount of angular change for that right angle. The surface

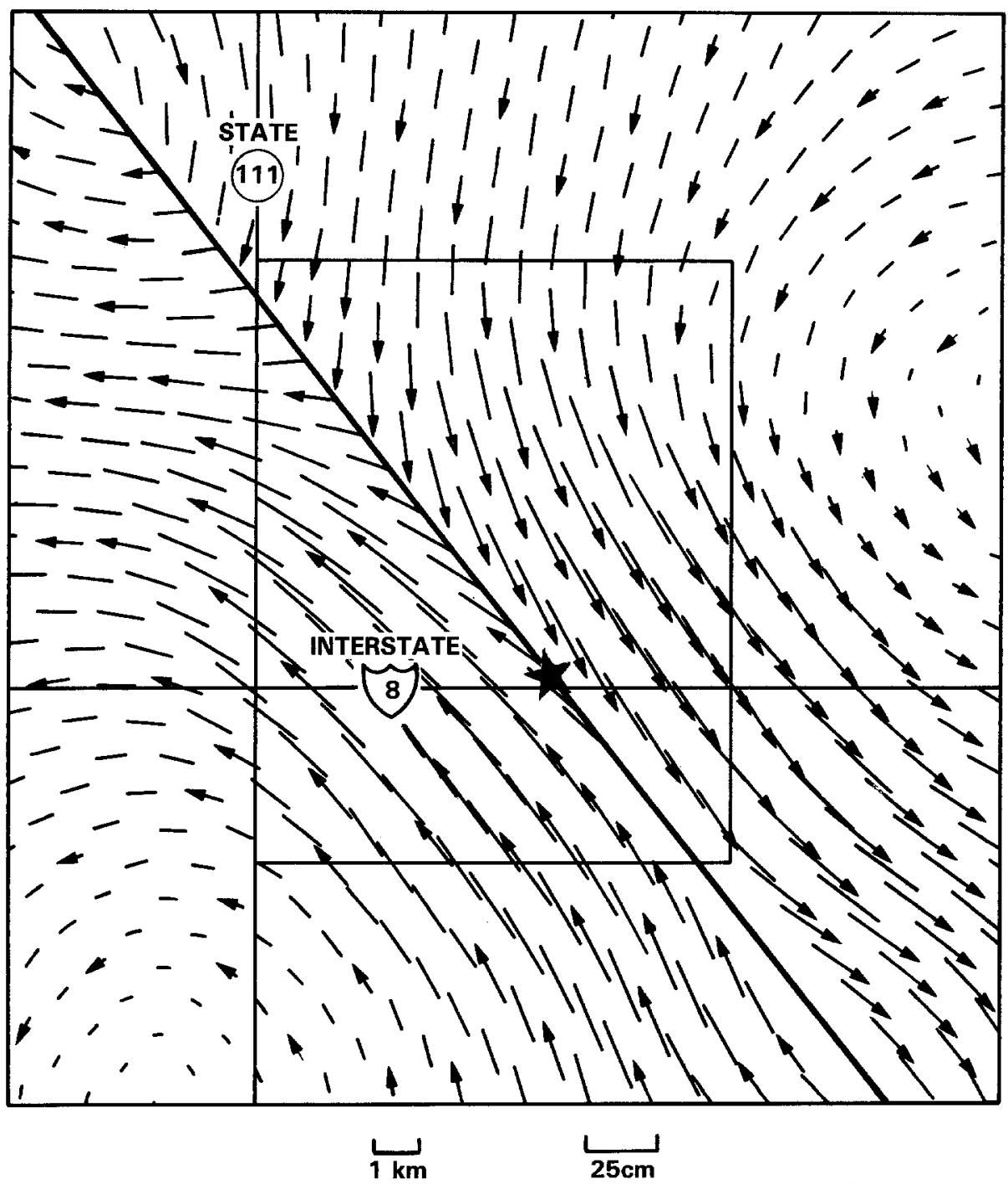

FiG. 5. Calculated static horizontal displacements from the "split-node" modeling, based on the Hartzell and Heaton (1982) fault plane dislocations. These values were obtained by interpolation of the finite element output through fitting the vectors on a surface passing through the nearest eight neighbors (less at edges).

motions of the model were used to calculate the predicted changes in the geodetic observations through the equations given below.

Consider a baseline between stations $i$ and $j$, which forms one side of a survey triangle. Define the quantities $x$ and $y$ as the differences

$$
\begin{aligned}
& x=X_{i}-X_{j} \\
& y=Y_{i}-Y_{j}
\end{aligned}
$$




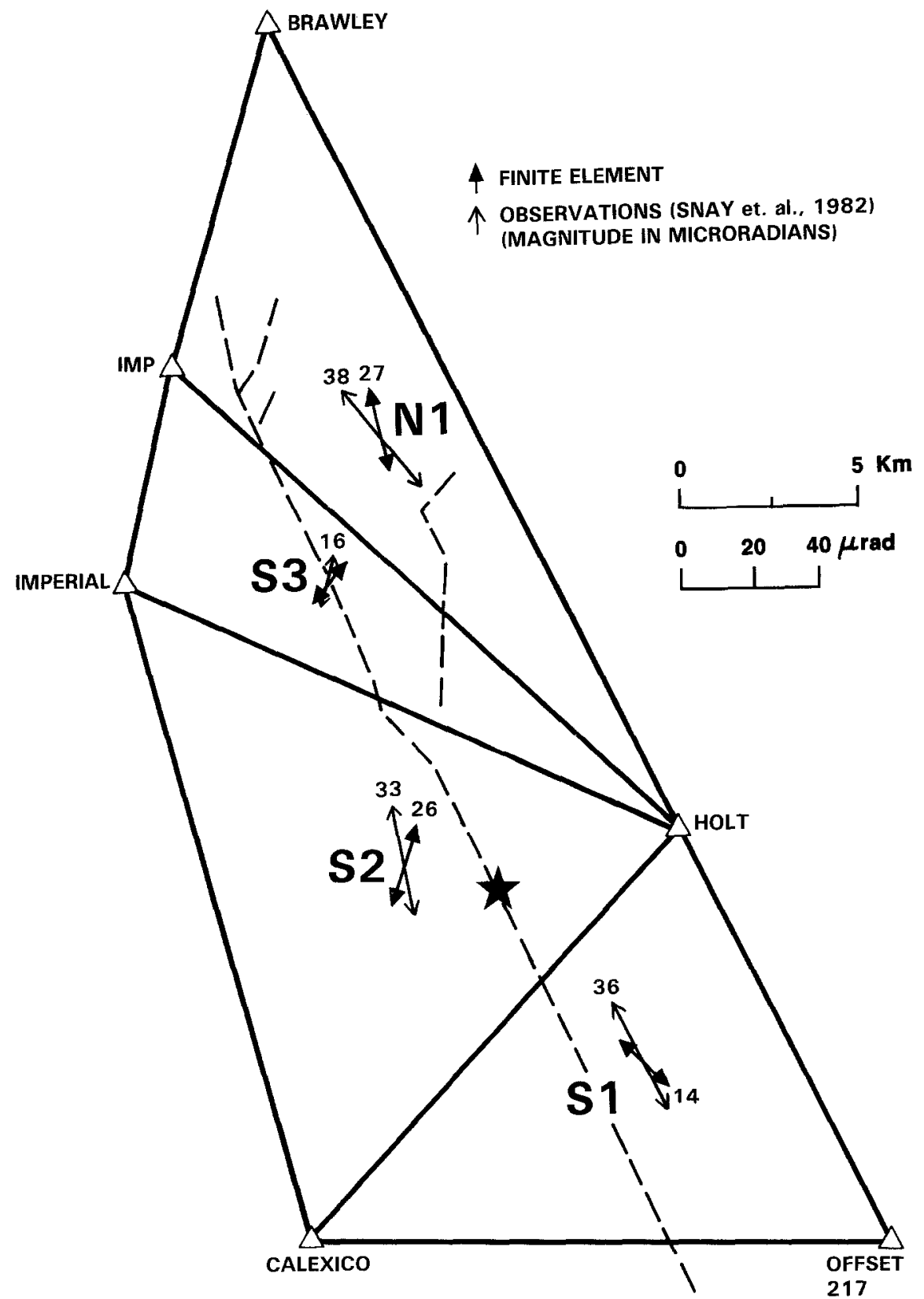

FIG. 6. The shear strain from the same model as Figure 5, but calculated at points to match the observed values as given by Snay et al. (1982). The star on the fault marks the origin of the finite element grid.

where $X_{i}, Y_{i}$ are the station coordinates.

The perturbations in these quantities by the earthquake displacements (assuming that all are small compared to $x$ and $y$ ) are

$$
\begin{aligned}
& \Delta x=u_{i}-u_{j} \\
& \Delta y=v_{i}-v_{j}
\end{aligned}
$$


where $u_{i}$ are the $x$ displacements and $v_{i}$ are the $y$ displacements. Then the change in length $L$ of the side is, to first order, given by

$$
\Delta L=[x \Delta x+y \Delta y] / L
$$

and also by

$$
\Delta L=\left[x^{2} \epsilon_{11}+x y \zeta+y^{2} \epsilon_{22}\right] / L
$$

where

$$
\begin{aligned}
\epsilon_{11} & =\frac{\partial u_{x}}{\partial x} \\
\epsilon_{22} & =\frac{\partial u_{y}}{\partial y} \\
\zeta & =\frac{\partial u_{x}}{\partial y}+\frac{\partial u_{y}}{\partial x}
\end{aligned}
$$

Now the other two sides give two similar equations, which can clearly be inverted for $\epsilon_{11}, \epsilon_{22}, \zeta$, in terms of the calculated finite element displacements $u_{i}, v_{i}$. The shear strains of Snay et al. are then related to these quantities by

$$
\begin{aligned}
\gamma_{1} & =\epsilon_{11}-\epsilon_{22} \\
\gamma_{2} & =\zeta \\
\psi & =\frac{1}{2} \tan ^{-1}\left(\gamma_{1} / \gamma_{2}\right)+\left(\pi / 2 \text { if } \gamma_{2}>0\right) .
\end{aligned}
$$

The agreement between the observations reduced by Snay et al. and the predictions of the finite element calculations based on Hartzell and Heaton's fault plane motions is reasonably good with the exception of triangle $S_{1}$. However, this triangle failed by an order of magnitude the test for linearity of the aseismic strain accumulation removed to produce the coseismic result imposed by Snay et al. (1982) in testing their results. For the rest of the triangles, small changes in the regional aseismic strain rates for 1979 could bring the geodetic values into good agreement with the model predictions. The agreement could alternatively by improved by increasing the fault slip and slightly changing the strike at depth appropriately. Considering the usual difference between geodetic and seismic moments due to the different time scales involved, the agreement is quite good.

Now let us turn to the stress-driven models. The physical model is an asperity (which is locked) surrounded by a region which is partially pinned by the asperity and partially slips in response to the tectonic stress. The tectonic stress (see bottom, Figure 1), which is developed in the entire grid, is produced by application of a uniform shear strain at the boundaries, corresponding in magnitude to an accumulated potential slip of $330 \mathrm{~cm}$. The value of the potential slip is just the stress level at depth required to overcome the fault frictional shear strength as shown in Figure 7 , converted to slip using the shear modulus. The developed tectonic shear stress on the fault plane is shown by the dashed line in Figure 7. The fault frictional shear 
strength that resists the tectonic shear is depth-dependent, and was derived from high-pressure soils loading experiments (R. Scott, personal communication, 1982). The solid line in Figure 7 shows these experimental results obtained from data on soils in the context of a Coulomb friction theory (see, e.g., Jaeger and Cook, 1969, p. 87). The resulting difference, where the tectonic shear stress on the fault exceeded the fault frictional shear strength, is shown by the bottom dashed curve of Figure 8

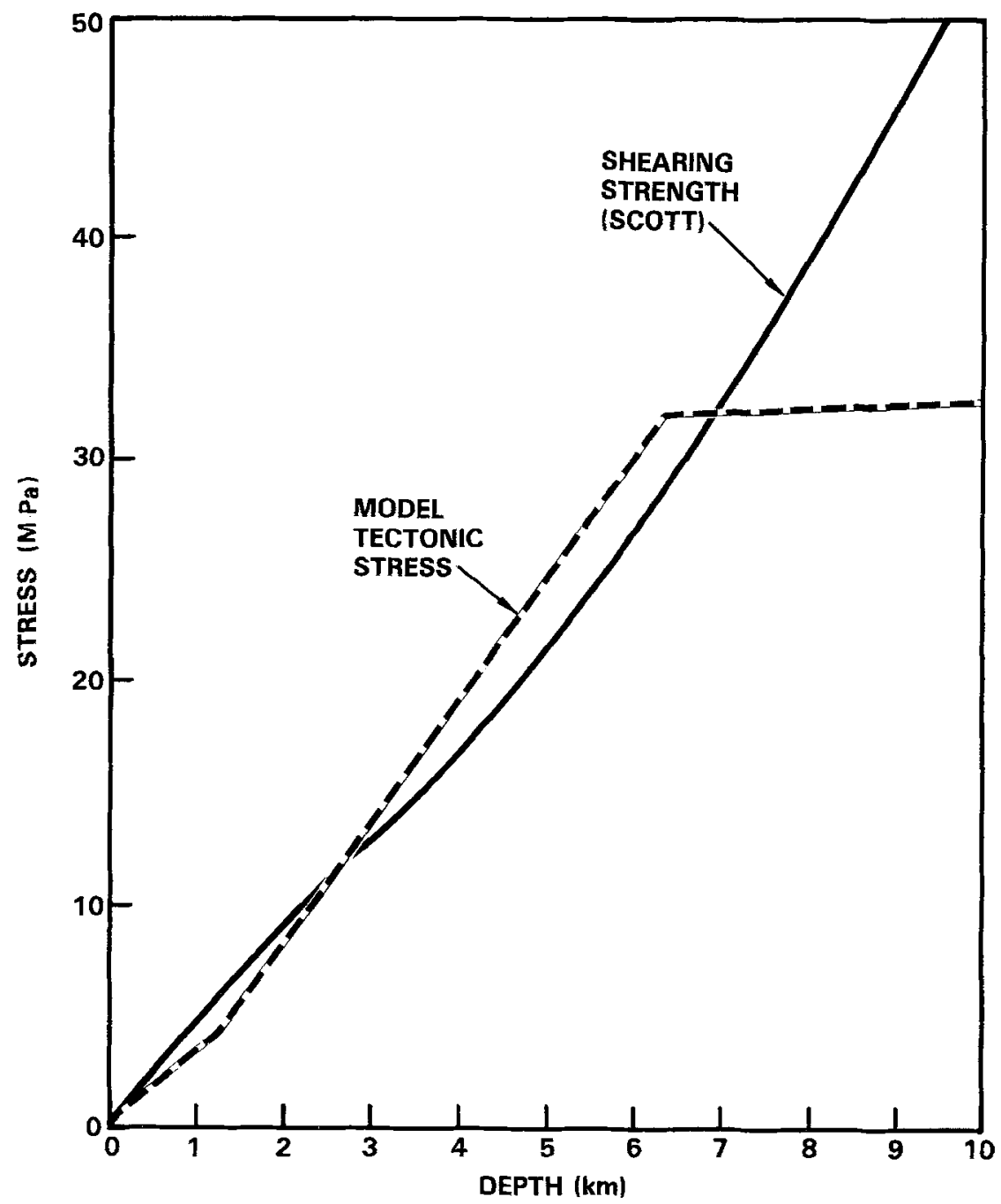

FIG. 7. The variation with depth of the model tectonic stress (dashed line) and the fault friction (solid line) that resists it. The actual stress values used were discrete values for the finite element modeling. The smooth curves are lines passing through the value at the depth of the center of each element.

(the solid curve will be explained further below). The difference gives the regional stress drop. The potential slip mentioned above was chosen on the basis of this particular frictional shear strength law, which has unknown applicability for the Imperial Valley. No inference about the existence of any seismic hazard should be made on the basis of this number. The models we have constructed do not seem to 
exclude the likely existence of such hazard based on other evidence (Archuleta, 1982a).

In attempting to reproduce the seismic slip on the fault from such a model, we could most simply achieve reasonable values by locally modifying the regional stress

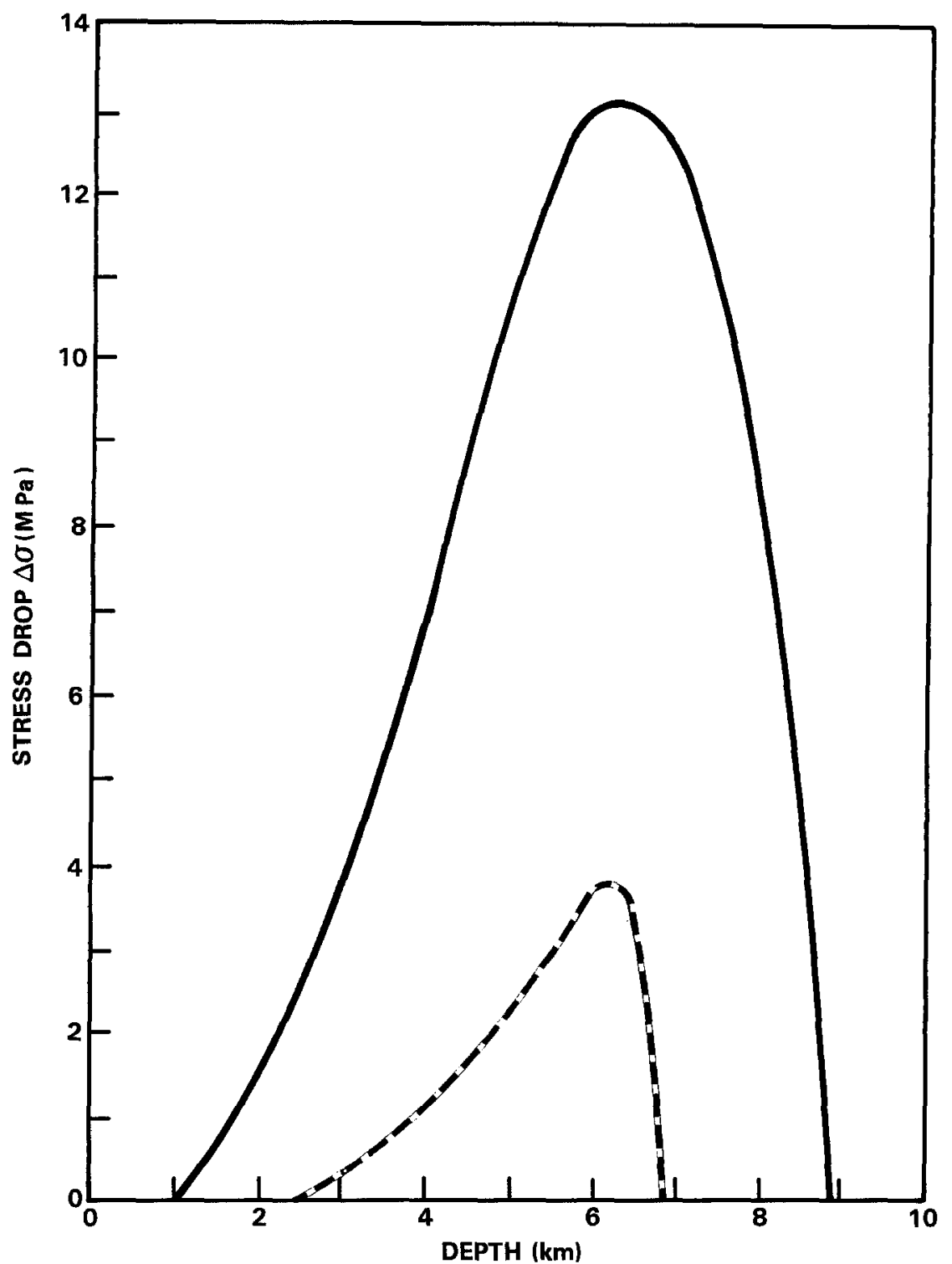

Fig. 8. The regional stress drop required for stress-driven models which match the slip on the fault from the seismic results of Hartzell and Heaton (dashed line), and the regional stress drop to produce surface displacements similar in size to the geodetic results of Mason et al., but not required by the geodetic results of Snay et al. (solid line).

drop (as described in the previous paragraph) in several locations. The fault friction was reduced in a patch around the asperity until the stress drop produced the maximum displacement as determined by Hartzell and Heaton (1983). The input stresses for this final model in the stress-driven cases are shown in Figure 9. The 


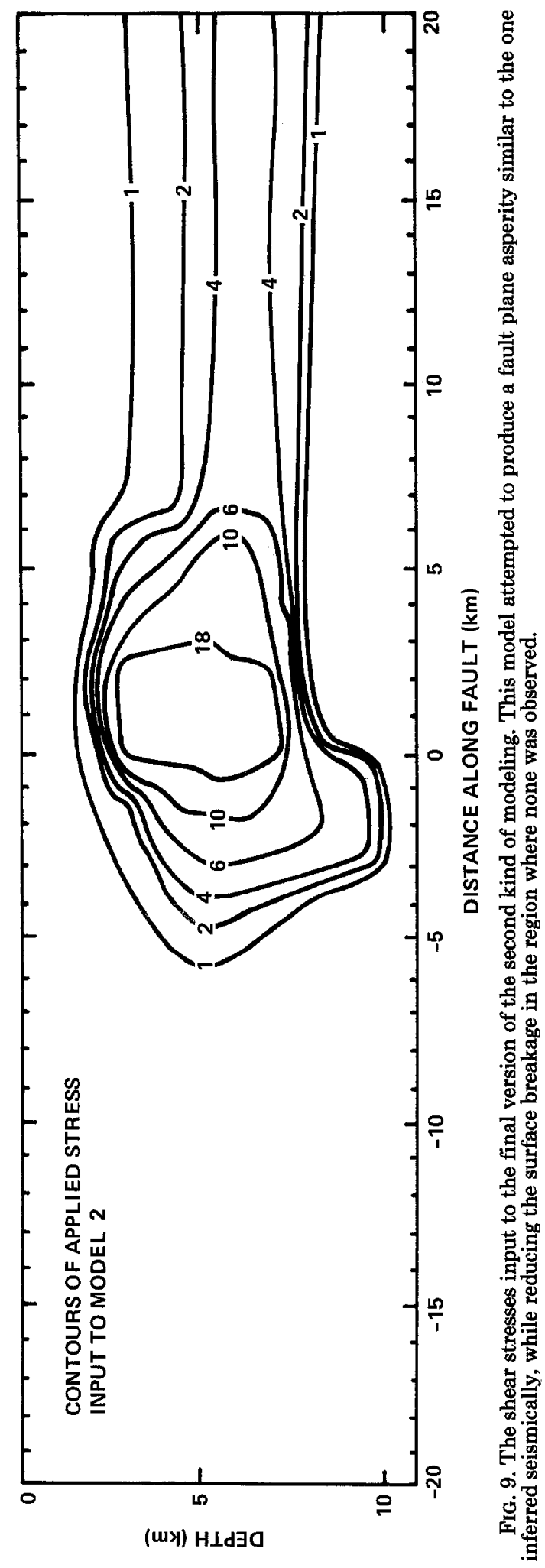




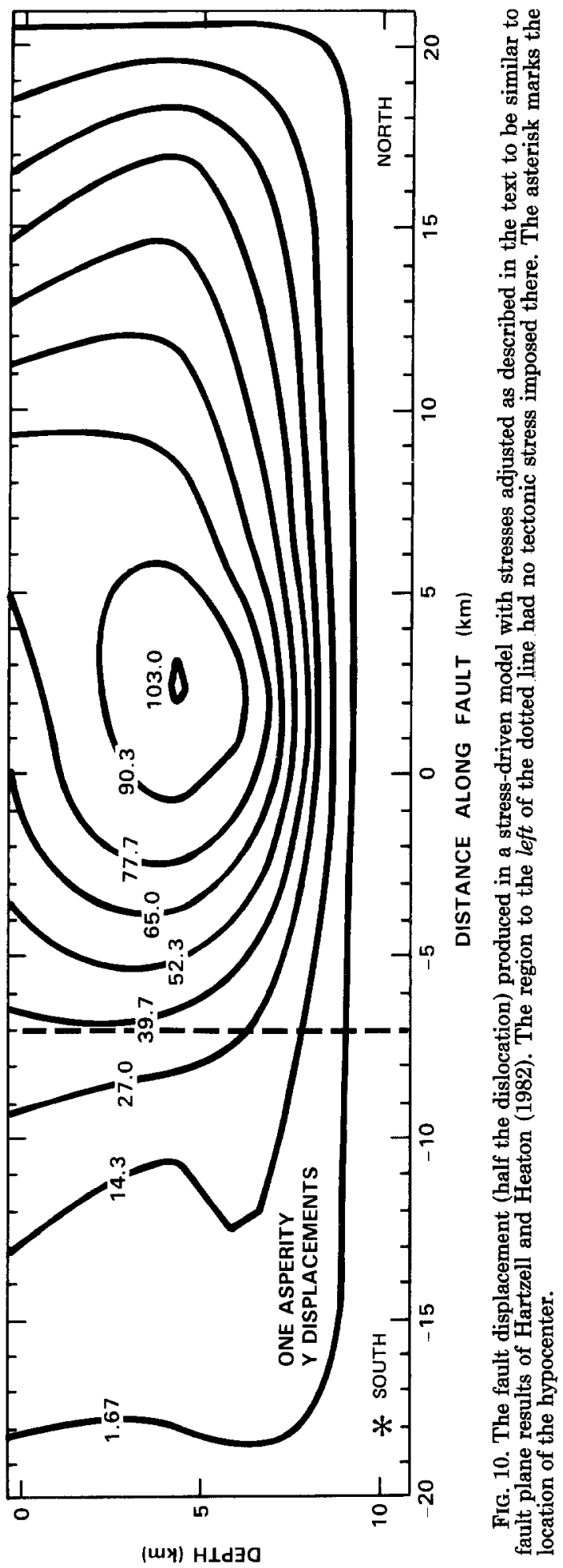


required stress drop at the asperity was found to be $18 \mathrm{MPa}$, in good agreement with the $20 \mathrm{MPa}$ found by Hartzell and Helmberger (1982). The applied stress drop was reduced to zero over the surface of the southern one-third of the active fault area (see Figure 9). This modification was required by the rapid reduction in the displacement, especially near the surface, as observed by Sharp et al. (1982) along this southern portion. The results from this model are shown in Figure 10 for the

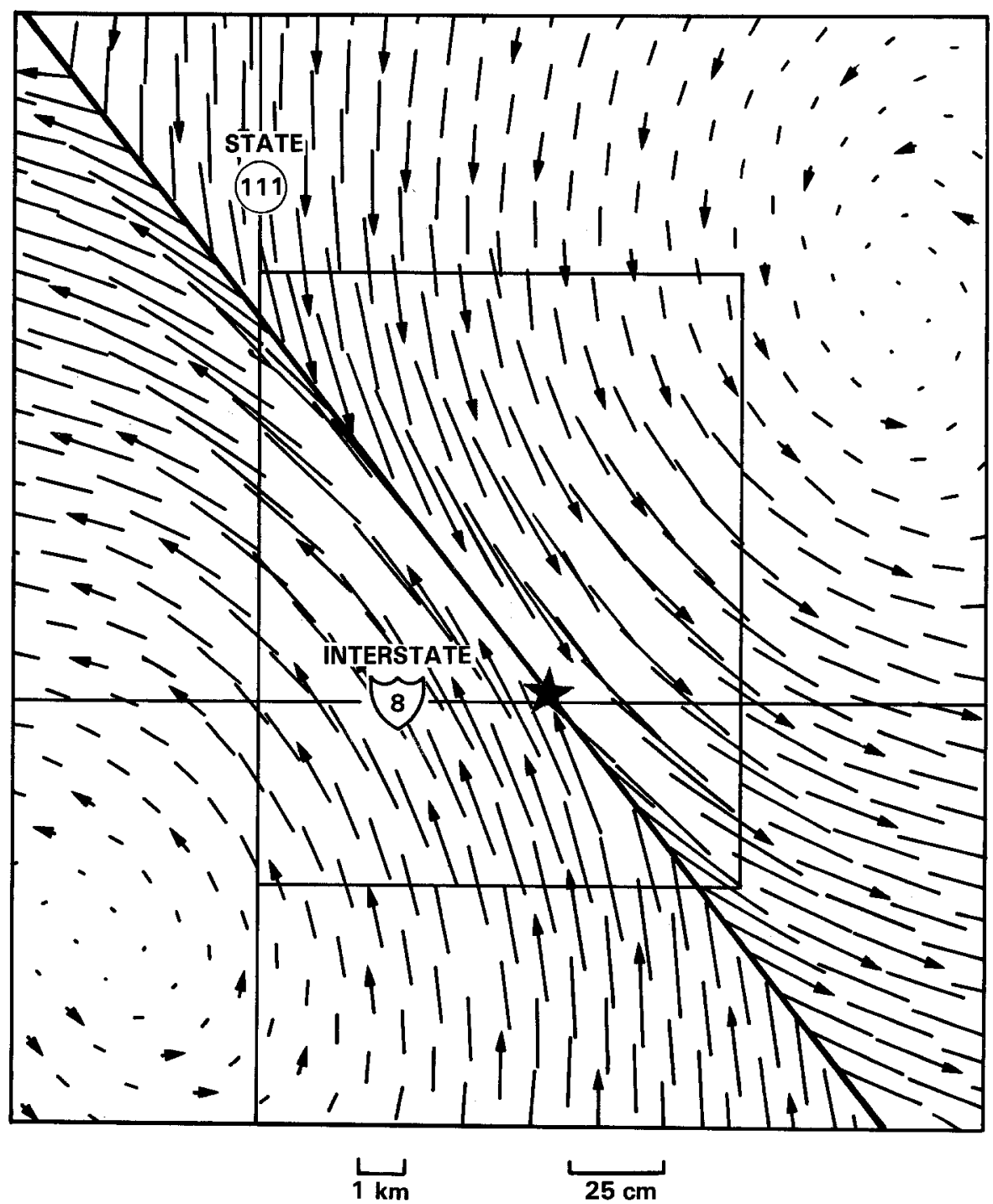

FiG. 11. The surface static horizontal displacements resulting from the same stress-driven model as Figure 9. The star marks the origin of the finite element grid.

calculated slip on the fault plane, and in Figure 11 for the surface displacements. The fault slip agrees quite well with the top of Figure 3. The surface horizontal motions calculated agree well with the displacement-based calculations as shown in Figure 6, where we have seen that this model matched at least most of the data of Snay et al. (1982).

For complete consistency, the yield stress in a small region near the hypocenter 
must be lowered so that motion can start. In Hartzell and Heaton's time-dependent motions, the motions nearly die off completely as they go north from the hypocenter until the region where stress is applied is reached. The Hartzell and Heaton model would not be expected to match the observations of actual surface breakage (Sharp et al., 1982), but in general their model gives the qualitative trend of the surface motions correctly. Note that no surface breakage was observed over this southern portion following the 1979 earthquake and also that the southern part of the fault experienced maximum surface offset during the 1940 El Centro earthquake (Sharp et al. 1982). All these factors together suggest that the 1940 earthquake may have relieved the majority of the stress to the south, and did not relieve much of the stress on the region that experienced surface rupture in 1979. Archuleta (1982a) has reached a similar conclusion on the basis of regional strain rates for the Imperial Valley.

This final model incorporated qualitative input from surface motions observed geodetically, surface breakage, and inferred slip on the fault plane. The distinction between this model and the results of the first type of model may seem to have become a little blurred. However, in reaching this second model, we did not use the stresses produced in the first type of model. (In fact, they would be quite difficult to compute for the fault plane.) The input for this final model was achieved by exploring heuristically the numerical values input for the stresses. We make no claims for uniqueness, but only maintain that there exists an interesting model of this sort which can partly reconcile these disparate data sets.

\section{An Additional Geodetic Data SeT}

A very preliminary reduction of a mekometer network in the Imperial Valley is available as a U.S. Geological Survey final report on changes of line lengths (Mason et al., 1981) from 1978 to 1980 . One figure from this report is reproduced as Figure 12, which shows surface horizontal displacements from Mason et al. (1981) thought to be dominated by the coseismic motions. The brief text does not describe the procedures and assumptions in producing the figures. A considerable difference in emphasis exists between this geodetic data set and the published results of Snay et $a l$., who examine the time dependence of their data and explicitly attempt to remove linear trends in time to attempt to isolate a coseismic part of their results. The lines of Mason et al. have not been so extensively sampled in time, and they understandably found it easier to assume that the Imperial Valley event would dominate the signatures found in the data.

The results for the surface motions predicted from Hartzell and Heaton's fault plane motions are shown in Figure 5. When compared with Figure 12, the pattern is reasonable, but the scale is quite different. The calculated maximum displacements are approximately $\pm 40 \mathrm{~cm}$ close to the fault over the asperity. The elastic moduli of the surface layer were varied to both weaker than the nominal value in Table 1, and also to be the same as in the layer at 2.5 to $5.0 \mathrm{~km}$ depth, without significant change in the surface motions. Some striking asymmetries exist in Figure 11 , which are naturally not present in the finite element model, since the grid is based on a $90^{\circ}$ dip of the fault plane. The northeast quadrant of Figure 11 has a region in which the displacements actually increase as the distance from the fault increases. Of course, this could result from deep slip on the fault, but for a vertically oriented fault plane, one would still expect the displacements to be somewhat symmetric. Near the center on the northeast side is a region in which the motions 


\section{STATION DISPLACEMENTS BETWEEN 1978 AND 1980}

STATE

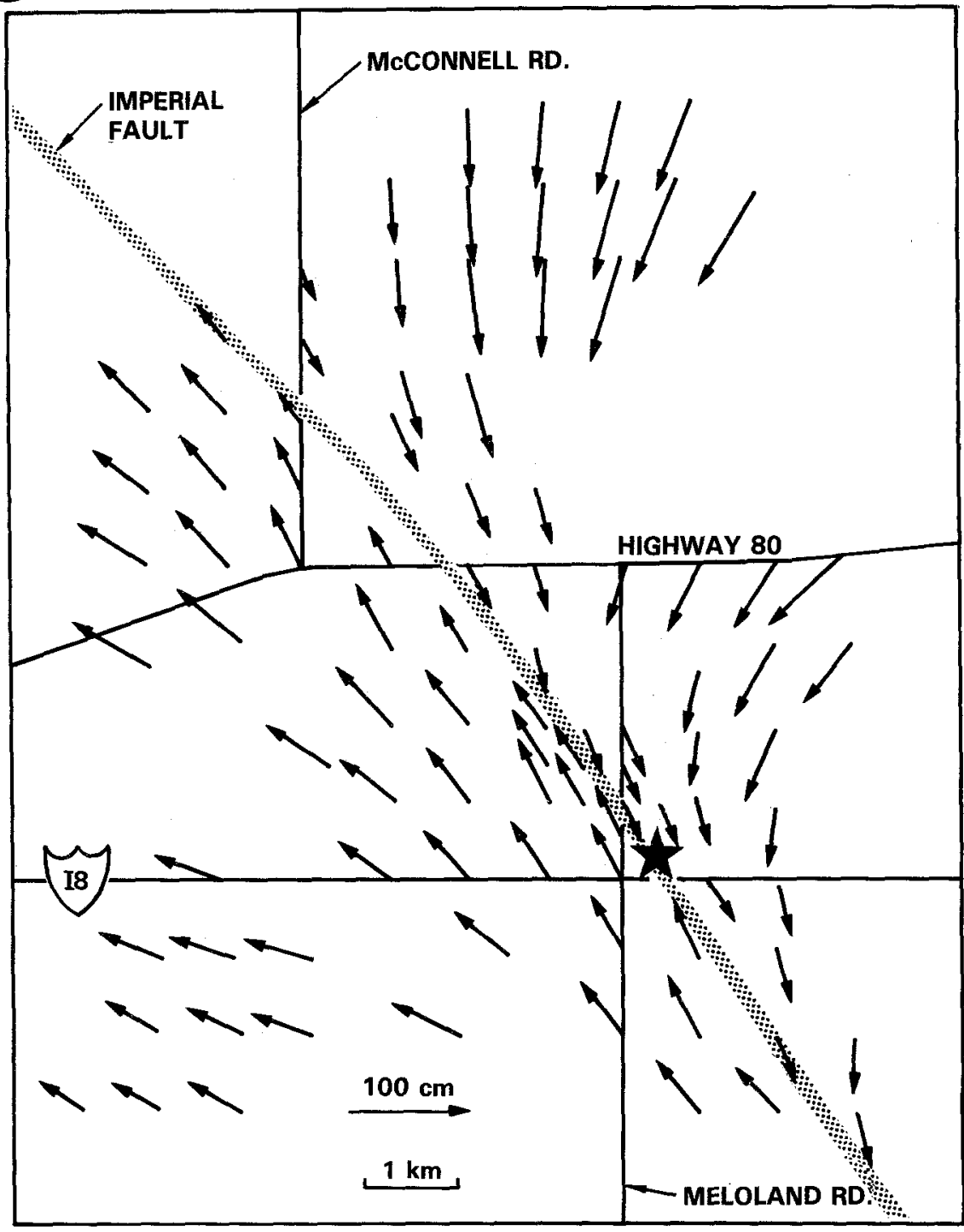

FIG. 12. The horizontal surface motions derived from the Imperial Valley mekometer network line length changes from 1978 to 1980 by Mason et al. (1981). The star on the fault trace marks the origin at the finite element grid.

have very large components normal to the fault which are not mirrored on the opposite side of the fault. Models were run in which the fault plane was prescribed as dipping up to $10^{\circ}$ from the vertical. This amount of dip, which is the most that the seismic results of Hartzell and Heaton (1983) would permit, did not introduce enough asymmetry to resemble these patterns. Other models have different dips (e.g., Archuleta, 1982a) and point up the need to reconcile these discordant models. 


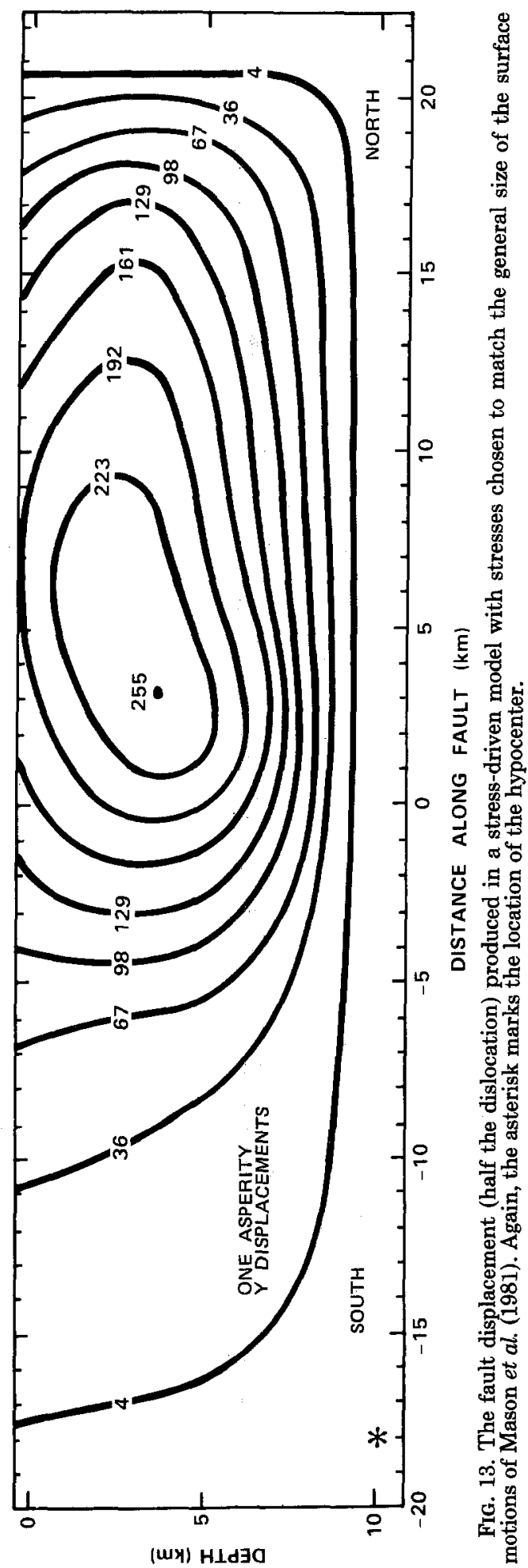


Of course these patterns could be due to local surface anomalies, subsidence, or other inhomogeneous variations in properties. The presence of other faults is well established in this region, and more will be said about these below.

These observations seem to suggest that the motions shown by Mason et al. have perhaps incorporated substantial local subsurface slip, particularly in the lines which were remeasured after up to 2 yr between observations. The amount of shallow slip required cannot be determined uniquely, but we shall see below that scaling-up the Hartzell and Heaton slip by a factor of 2.5 to 3 could reproduce much of the difference. Of course this scaling-up would strongly violate the observed seismic moment. Slip at depths below our active fault area (deeper than $10 \mathrm{~km}$ ) could also be occurring, but for this deep slip to be important within $5 \mathrm{~km}$ of the fault, the displacements at large distances from the fault would become unreasonably large. Both of these explanations seem highly unlikely. Very shallow local slip, on the order of 50 to $90 \mathrm{~cm}$, would account for the observations.

Models driven by stress drop can be produced which match the general size of the Mason results. The stress drop required is shown by the top curve in Figure 8 . (Such models do not, however, produce the details of the asymmetries as shown in connection with Figure 11.) The regional stress drop is about three times larger than in models which produce displacements similar to the seismic results. The displacement on one side of the fault for such a model is shown in Figure 13. The character of the displacement near the asperity was simply scaled up by a factor of three from the stress drop as discussed above, except that no regional stress drop has been removed to the south. (Even if the stress there is removed, as we tried in some models, the calculated surface breakage above this region is very substantial in contradiction of observation.) The calculated seismic moment of this model is 12 $\times 10^{25}$ dyne-cm, as compared with the observed (5 to 6.5$) \times 10^{25}$ dyne-cm from many different analyses (Hartzell and Helmberger, 1982; Kanamori and Regan, 1982).

\section{CONCLUSIONS}

Further investigation should attempt to define a more nearly coseismic subset of the Mason et al. results. Results by Crook et al. (1982) appear to be showing just such a subset, and these limited results are in better agreement with the numerical models given above. This paper, however, seems to be an earlier stage of the analysis presented in Mason et al. (1981). This apparent contradiction is unresolved at present. The inclusion of the Brawley fault should be required for very detailed modeling, since Archuleta (1982b) finds that up to 5 percent of the seismic moment of this event is due to motion on the Brawley fault. The actual curved geometry of the Imperial fault, here considered only as a vertical plane, could be included in more refined models. Another candidate for additional modeling is slip at depth on the Superstition Hills fault (Fuis, 1982). Johnson (1979) finds earthquake swarms are initiated on lines trending northeast from the Imperial fault. The crustal structures responsible could also be important to the surface motions if they could be identified and modeled.

We have presented finite element models of two kinds: displacement-driven and stress-driven. The two types of modeling have been shown to be fairly consistent with each other. The results are in good agreement with seismically determined slip on the fault and with one of two geodetic data sets. The disagreeing data set may be influenced by near-surface creep, and further analysis is required. 


\section{ACKNOWLEDGMENTS}

We are very indebted to Professor R. F. Scott of Caltech Earthquake Engineering for his calculations relating to the fault friction model and for helpful comments on the manuscript. We thank $S$. H. Hartzell and T. H. Heaton for many valuable discussions. The comments of an anonymous reviewer have resulted in substantial improvements to the paper. The work described in this paper was carried out by the Jet Propulsion Laboratory, California Institute of Technology, under contract with the National Aeronautics and Space Administration.

\section{REFERENCES}

Archuleta, R. J. (1982a). Analysis of near-source static and dynamic measurements from the 1979 Imperial Valley earthquake, Bull. Seism. Soc. Am. 72, 1927-1956.

Archuleta, R. J. (1982b). Presentation at 1982 Fall American Geophysical Union Meeting.

Chavez, D., J. Gonzalez, A. Reyes, M. Medina, C. Duarte, J. N. Brune, F. Vernon III, R. Simons, L. K. Hutton, P. T. German, and C. E. Johnson (1982). The Imperial Valley Earthquake of October 15, 1979. Main-shock location and magnitude determination using combined United States and Mexican data, U.S. Geol. Surv. Profess. Paper 1254, 51-54.

Crook, C. N., R. G. Mason, and P. R. Wood (1982). Geodetic measurements of horizontal deformation on the Imperial fault, U.S. Geol. Surv. Profess. Paper 1254, 183-191.

Elders, W. A., R. W. Rex, T. Meidav, P. T. Robinson, and S. Biehler (1972). Crustal spreading in southern California, Science 178, 15-24.

Fuis, G. S. (1982). Displacement on the Superstition Hills fault triggered by the earthquake, U.S. Geol. Surv. Profess. Paper 1254, 145-154.

Fuis, G. S., W. D. Mooney, J. H. Healy, G. A. McMechan, and W. J. Lutter (1981). Seismic refraction studies on the Imperial Valley region, California-Profile Models, a Traveltime Contour Map, and a Gravity Model, U.S. Geol. Surv., Open-File Rept. 81-270.

Hartzell, S. H. and T. H. Heaton (1983). Inversion of strong-ground motion and teleseismic waveform data for the fault rupture history of the 1979 Imperial Valley, California, Earthquake, Bull. Seism. Soc. Am. 73, 1553-1583.

Hartzell, S. and D. Helmberger (1982). Strong motion modeling of the Imperial Valley earthquake of 1979, Bull. Seism. Soc. Am. 72, 571-596.

Hughes, T. J. R. and R. L. Taylor (1978). Unconditionally stable algorithms for quasi-static elasto/ viscoplastic finite element analysis, Comput. Struct. 8, 169-173.

Jaeger, J. C. and N. G. W. Cook (1969). Fundamentals of Rock Mechanics, Methuen \& Company, Limited, London, England.

Johnson, C. E. (1979). CEDAR-An approach to the computer automation of short-period local seismic networks; seismotectonics of the Imperial Valley of Southern California, Ph.D. Thesis, $343 \mathrm{pp}$.

Kanamori, H. and J. Regan (1982). Long period surface waves, U.S. Geol. Surv., Profess. Paper 1254, $55-58$.

Lomnitz, C., F. Mooser, C. R. Allen, and W. Thatcher (1970). Seismicity and tectonics of the northern Gulf of California Region, Mexico, Geofisica Internacional 10, no. 2.

Mason, R. G., C. N. Crook, and P. R. Wood (June 1981). Mekometer measurements in the Imperial Valley, Final Report U.S. Geol. Surv. Contract 983901.

Melosh, H. J. and A. Raefsky (1980). The dynamical origin of subduction zone topography, Geophys. J. R. Astr. Soc. 60, 333-354.

Melosh, H. J. and A. Raefsky (1981). A simple and efficient method of introducing faults into finite element calculations, Bull. Seism. Soc. Am., 71, 1391-1400.

Olson, A. H. and R. J. Apsel (1982). Finite faults and inverse theory with applications to the 1979 Imperial Valley earthquake, Bull. Seism. Soc. Am. 72, 1969-2001.

Savage, J. C., W. H. Prescott, M. Lisowski, and N. King (1979). Deformation across the Salton Trough, California 1973-1977, J. Geophys. Res., 84, 3069-3079.

Savage, J. C., W. H. Prescott, M. Lisowski, and N. King (1981). Strain accumulation in southern California, 1973-1980, J. Geophys. Res. 86, 6991-7001. 
Sharp, R. V., J. J. Lienkaemper, M. G. Bonilla, D. B. Burke, B. F. Fox, D. G. Herd, D. M. Miller, D. M. Morton, D. J. Ponti, M. J. Rymer, J. C. Tinsley, J. C. Yount, J. Kahle, E. W. Hart, and K. E. Sieh (1982). Surface faulting in the Imperial Valley, U.S. Geol. Surv. Profess. Paper 1254, 119-143.

Snay, R. A., M. W. Cline, and E. L. Timmerman (1982). Horizontal deformation in the Imperial Valley between 1934 and 1980, J. Geophys. Res. 87, 3959-3968.

Wilson, E. L. and H. H. Dovey (1978). Solution or reduction of equilibrium equations for large complex structures, Adv. Eng. Software 1, 19-25.

Zienkiewicz, O. C. (1977). The Finite Element Method, McGraw-Hill, London, England.

Jet Propulsion Laboratory

California Institute of Technology

Pasadena, California 91109

Manuscript received 22 July 1983 